\title{
THE ACQUISITION OF THE QUANTITATIVE PRONOUN BY ENGLISH AND FRENCH LEARNERS OF L2 DUTCH: AN EXPERIMENTAL STUDY BASED ON AN ELICITED IMITATION TASK
}

\author{
Petra Sleeman and Sanne Berends*
}

\begin{abstract}
It has been argued that an Elicited Imitation Task gives better insights into the L1 acquisition of the Dutch quantitative pronoun ER than a Picture Elicitation Task. In this paper the results of an Elicited Imitation Task submitted to adult L1 French and L1 English learners of L2 Dutch are presented and compared to earlier results of a Grammaticality Judgment Task. Like Dutch and unlike English, French uses a quantitative pronoun in noun ellipsis constructions with a numeral. Earlier results revealed that in the Grammaticality Judgment Task there was no significant difference between both groups of L2 learners in their acceptance of $E R$, although this was predicted on the basis of possible transfer from their L1. In the Elicited Imitation Task, however, the L1 English learners repeated ER significantly less often than the L1 French learners. This can be attributed to the different nature of the two types of test.
\end{abstract}

Keywords: quantitative pronoun, L2 acquisition, Elicited Imitation, Dutch

\section{Introduction}

Just like several Romance languages (French, Italian, Catalan) Dutch has a quantitative pronoun which is obligatorily used in combination with an indefinite nounless noun phrase introduced by a numeral in object position. In Dutch the quantitative pronoun is $E R$. The numeral quantifies over a set that is present in the context. In (1) this is a set of cats:

$$
\begin{aligned}
& \text { Katten? Ik heb *(er) drie. } \\
& \text { Cats? I have ER three } \\
& \text { 'Cats? I have three.' }
\end{aligned}
$$

In French the quantitative pronoun is $E N$. It is used in the same way as Dutch $E R$ in quantitative contexts, i.e. its use is obligatory in combination with a nounless NP containing a remnant numeral in object position:

(2) Paul voulait acheter un nouveau stylo. Il *(en) a acheté deux.

Paul wanted to buy a new pencil he EN has bought two

'Paul wanted to buy a new pencil. He has bought two.'

English, on the contrary, does not have a quantitative pronoun. This means that an elliptical NP can be used in object position without an additional support:

(3) John likes fast cars. He has two.

\footnotetext{
* University of Amsterdam. Corresponding author: p.sleeman@uva.nl.
} 
Berends et al. (2017) investigated the L2 acquisition of the quantitative pronoun $E R$ in contexts such as (1) by L1 French and L1 English learners of Dutch by means of a Grammaticality Judgment Task. Since French uses a quantitative pronoun, whereas English does not have one, they expected the results of the L1 English learners to differ significantly from the results of the L1 French learners of Dutch. However, this prediction was not borne out. Berends et al. (2010) investigated the L1 acquisition of the quantitative pronoun $E R$ by Dutch children by means of a Picture Elicitation Task and an Elicited Imitation Task. They show that the Picture Elicitation Task provided many constructions in which $E R$ was avoided, whereas in the Elicited Imitation Task the children either used or left out $E R$, without resorting to alternative constructions. The authors were therefore positive about the use of an Elicited Imitation Task to investigate the acquisition of $E R$.

Influenced by Berends et al.'s (2010) positive judgments about the Elicited Imitation Task for the study of the acquisition of $E R$ by children, we will use this test to study the L2 acquisition of ER by L1 French and L1 English learners of Dutch in this paper. We will compare the results to the results obtained by Berends et al. (2017) and Berends et al. (2018) based on a Grammaticality Judgment Task and we will evaluate the use of both tests to study the L2 acquisition of $E R^{1}$.

The paper is organized as follows. In section 2 previous research on the L1 and L2 acquisition of $E R$ is summarized. In section 3 the evaluation of the use of an Elicited Imitation Task in previous literature is presented. Section 4 serves to expose our research question, to introduce the participants to this study and to explain our methodology including the analysis of the results. The results are presented and discussed in sections 5 and 6 , respectively. Some concluding remarks are provided in section 7.

\section{Previous research on the $L 1$ and $L 2$ acquisition of $E R$}

Sleeman and Hulk (2013) studied the emergence of the quantitative pronoun in the spontaneous speech of five French and five Dutch children available in CHILDES (MacWhinney 2006). They show that whereas the French children start using the quantitative pronoun around the age of $1 ; 11$, the Dutch children start using the quantitative pronoun around the age of $2 ; 4$. The authors found that at the early ages of acquisition the use of the quantitative pronoun is optional, but if it is used, it is pragmatically and syntactically correctly used.

Dutch has four types of ER: prepositional, quantitative, locative and expletive (Bennis 1986). Van Dijk and Coopmans (2013) and Berends et al. (2016) studied the spontaneous speech of Dutch children in CHILDES in order to establish the respective orders of emergence. In both studies it was shown that the quantitative pronoun emerges relatively late with respect to other types of $E R$.

\footnotetext{
${ }^{1}$ The research for this paper was done in the framework of Sanne Berends' $\mathrm{PhD}$ project carried out at the University of Amsterdam and supervised by Aafke Hulk, Jeannette Schaeffer and Petra Sleeman. This paper is loosely based on chapter 5 of Sanne Berends' PhD dissertation (in progress).
} 
Van Hout et al. (2011) investigated the acquisition of the Dutch quantitative pronoun $E R$ by 29 typically developing five-year old monolingual Dutch children by means of a Picture Elicitation Task (PET), which was a guessing game. The experimenter asked, for instance, if grandmother took three suitcases with her, which was a wrong guess, and the child was expected to correct the number in a quantificational construction. However, in many cases the child simply said 'no', followed by a numeral, such as 'no, two'. Discarding non-complete answers (without a verb) from the analysis, i.e. 145 out of 348 answers, the authors show that only $35.5 \%$ of the complete sentences contained the targeted pronoun $E R$. Of the $64.5 \%$ of remaining answers, $49.1 \%$ contained a full noun phrase instead of $E R$ plus elliptical noun phrase, in $9.7 \%$ of the cases $E R$ was omitted and in $5.7 \%$ of the cases the pronoun was doubled by a noun phrase. The control group consisting of adults produced in $100 \%$ of the cases ER in the PET.

Berends et al. (2010) show that in an Elicited Imitation Task (henceforth EIT) the same 29 typically developing children they tested (aged between $5 ; 2$ and $6 ; 1$ ) performed much better than in the PET. In the EIT a short story was told. The child had to repeat the last sentence containing a numeral and $E R$, such as (4):

$$
\begin{aligned}
& \text { De jongen koopt er twee. } \\
& \text { the boy buys ER two } \\
& \text { 'The boy buys two.' }
\end{aligned}
$$

In the EIT the children repeated $E R$ correctly $80.7 \%$ of the times (and the adult control group in $100 \%$ of the cases). The errors, $18.4 \%$, were almost all due to $E R$-omission. Since the PET allowed for too much variation, such as the use of a full NP, the authors judge that the EIT gave more reliable results in their research on the acquisition of ER. They express, however, also some hesitations with respect to the EIT. That is, they wonder if the high number of target answers cannot be due to simple parroting, because the experimental sentences, such as (4), were rather short (6-7 syllables). Since more than half of the children sometimes omitted $E R$, the authors conclude that the test was not too easy, and that the children could not only rely on their memory. However, they also recommend improving the test by adding more syllables and by varying in complexity.

The L2 acquisition of the quantitative pronoun ER by 25 adult L1 French learners and 25 adult L1 English learners of L2 Dutch has been investigated by Berends et al. (2017) by means of an untimed online aural Grammaticality Judgment Task (henceforth GJT). The test contained both grammatical and ungrammatical sentences in a randomized order $^{2}$. An example for a quantitative construction containing a numeral is given in (5). An introductory sentence was followed once by the grammatical answer in A and once by the ungrammatical answer in B. The participants were asked to judge the correctness of the answers:

\footnotetext{
${ }^{2}$ In this paper we only focus on quantitative constructions containing an elliptical noun phrase introduced by a numeral.
} 
(5) Intro

A correct

B incorrect
Zondag heb ik 3 appels gegeten Sunday have I three apples eaten 'On Sunday I ate 3 apples.'

Dinsdag heb jij ER 2 gegeten Tuesday have you ER two eaten 'On Tuesday you ate two.'

*Dinsdag heb jij $\varnothing 2$ gegeten Tuesday have you $\varnothing$ two eaten 'On Tuesday you ate two.'

Since French uses or omits the quantitative pronoun as it is done in the Dutch quantitative construction containing a numeral, it was predicted that the L1 French learners of Dutch would not significantly differ from the L1 Dutch speakers in their judgments of the A ("presence") and B ("absence") sentences. For the L1 English learners of Dutch it was predicted that they would accept the correct A sentences significantly less often than the L1 Dutch speakers and that they would reject the ungrammatical B sentences significantly less often than the L1 Dutch speakers. Furthermore, it was predicted that the French and English learners would differ significantly from each other in both "presence" and "absence". In the analysis the results of the grammatical sentences with $E R$ and the ungrammatical sentences without $E R$ were taken together. The results show a significant difference with respect to the condition "presence/absence", as in (1), between the 25 Dutch adult monolinguals of the control group and both the L1 French learners of Dutch $(p=0.0258)$ and the L1 English learners of Dutch $(\mathrm{p}=0.0036)$. The French and the English learners did not significantly differ from each other $(\mathrm{p}=0.3203)$.

Berends et al. (2018) analyzed the data of Berends et al. (2017) more precisely, distinguishing between grammatical and ungrammatical sentences. For ease of comparison with the L1 child data, we will focus on the grammatical sentences only. For the condition "presence" with a numeral the results are presented in Figure 1:

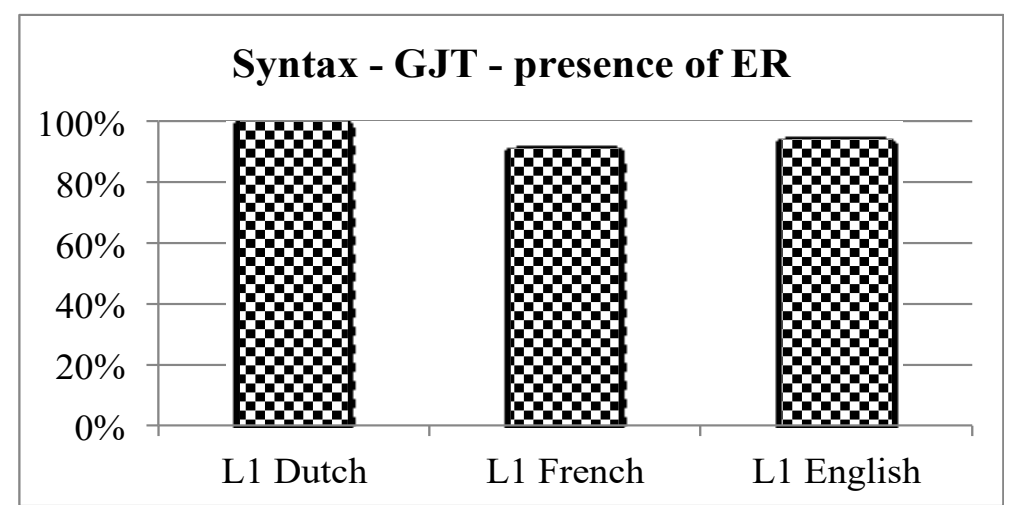

Figure 1. Acceptance of grammatical quantitative constructions with $E R$ 
It was shown that whereas the native speakers of Dutch accepted the use of $E R$ in grammatical sentences in $100 \%$ of the cases, the French learners of Dutch did so in $91 \%$ of the cases and the English learners of Dutch did so in $94 \%$ of the cases. The result of an ANOVA was not significant, $(F(2,71)=2.77, \mathrm{p}=0.069)$. This means that in the accurate sentences, in which $E R$ was present, the variance of the three L1 groups did not differ significantly: all groups scored at ceiling $(>90 \%)$. The separate linear regression models led to no significant differences between the groups either: L1 Dutch - L1 French, $(t(71)=-1.87, \mathrm{p}=0.065)$; L1 Dutch - L1 English, $(t(71)=0.65, \mathrm{p}=0.519)$; L1 French L1 English, $(t(71)=-1.16, \mathrm{p}=0.251)$. For the L1 English learners of Dutch the non-significant difference with the native speakers was not predicted. Furthermore, the non-significant difference between the results of the French and the English learners was not predicted.

At the beginning of this section it was shown that Berends et al. (2010) judged an EIT more appropriate for the study of the use of the quantitative pronoun $E R$ by Dutch children than a PET. In this paper we will use an EIT to investigate the acquisition of quantitative $E R$ by L2 learners of Dutch and we will evaluate it against the results of the GJT presented in Berends et al. (2018). In the next section we discuss the use of Elicited Imitation in acquisitional research.

\section{Elicited Imitation}

The Elicited Imitation Task (EIT), also called a Sentence Repetition Task or Sentence Imitation Task, has been used in linguistic research since more than 50 years. It was widely used in the seventies and early eighties for general assessment of L1 and L2 acquisition and language disorders and also for the assessment of the acquisition of specific phenomena. In the eighties communicative approaches became more important, which led to the regression of the EIT as an assessment tool, because it was judged to measure oral production in an unnatural way (Vinther 2002). More recent research has, however, revealed that Elicited Imitation (EI) is as good for the assessment of oral production in educational situations as other proficiency measures (van Moere 2012). Yan et al. (2015) analyzed 76 scientific publications in which the EI had been used. On the basis of their analysis, they argue that the EI is a valid method.

In EI the participant is asked to repeat a sentence that has just been read. If the sentence contains enough syllables (16 or more syllables for adults, see, e.g. Jensen and Vinther 2003), reliance on the short-term memory is not possible. A proficient participant will analyze the sentence and will reconstruct the sentence based on linguistic knowledge that is present in the long-term memory. This may lead to a sentence that is not identical to the stimulus. Grammatical features that are present in the stimulus and that have not been fully acquired may unconsciously be changed in accordance with the interlanguage of the learner (Bley-Vroman and Chaudron 1994).

EITs may contain grammatical and ungrammatical sentences. For children it has been shown that they are not keen to repeat ungrammatical sentences: they either say nothing or correct the sentence. The corrections are a good measure of linguistic abilities (Brown and Fraser 1964, Devescovi and Caselli 2007). 
One of the problems that have been observed while using the EIT is rote repetition. Therefore it has been argued that sentences should be long enough to avoid parroting. It has been shown that if sentences are long enough, learners make unconscious changes in their responses, reflecting their preference (Munnich et al. 1994, Erlam 2006). Furthermore it has been argued that after the sentence has been read, the participants should either wait 2-3 seconds before starting to repeat the sentence, should be distracted, e.g. by a short task (McDade et al. 1982) or should be asked a question about the meaning of the sentence (Erlam 2006). In some EITs, participants were allowed to hear the sentence more than once, if they were not able to repeat the sentence.

Since an EIT is a demanding task, participants may indeed not correctly repeat the sentences. This leads to the question of what to include in the analysis. We will present two cases, in which a different solution was created.

Van Boxtel (2005), see also van Boxtel et al. (2005), tested the acquisition of dummy subjects in Dutch by L1 speakers of German, French and Turkish. Dutch has two dummy subjects, het and er, alongside the use of a null subject. For L2 learners the acquisition of the distinction is notoriously complicated. According to van Boxtel, EITs are perfectly well suited to test the acquisition of phonologically non-salient elements like dummy subjects (see also Wu and Ortega 2013). All sentences of her EIT consisted of fifteen syllables. Because of the demanding nature of the EIT, the test sentences consisted of 6 grammatical and 6 ungrammatical sentences and 8 fillers. According to the author, both grammatical and ungrammatical sentences can be informative, because changes in both types of sentences can show that the L2 learner has not yet fully acquired the feature (see also, e.g. Hamayan et al. 1977, Munnich et al. 1994). Native speakers, on the other hand, are not supposed to change grammatical sentences.

The learners were allowed to hear the sentence one or two times again if they were not able to repeat (part of) the sentence. Besides a native control group, van Boxtel tested three groups of highly advanced L2 learners of Dutch: L1 speakers of a typologically related language (German), L1 speakers of a less related Indo-European language (French), and L1 speakers of a non-Indo-European language (Turkish). Van Boxtel's goal was to verify if L2 learners can reach a near native mastering of the use of dummy subjects, which would provide evidence against the Critical Period Hypothesis (Penfield and Roberts 1959, Lenneberg 1967). She hypothesized that the L1 German group would behave most native-like, followed by the L1 French group, followed in turn by the Turkish group.

In the analysis of the data, van Boxtel distinguished different categories, such as "no change in dummy subject", "predicted change in dummy subject", "change in dummy subject while not predicted", "other change in dummy subject than predicted" and three "other" categories, consisting of more dramatical changes or omissions in the sentence. Because of the heterogeneity of the data, van Boxtel did not perform a statistical analysis, but performed a qualitative analysis, considering a learner to perform within the range of the native speakers if all of the dummy subjects produced by the learner were also produced by at least one native speaker. Furthermore she compared the four groups with respect to each of the different categories in percentages. She found that among the L1 German speakers most native-like learners were found, followed by the French group. The Turkish group contained the lowest number of native-like learners. 
Van Boxtel attributed the difference to a breakdown that occurs when processing load exceeds participants' working memory capacity. If an L1 is typologically more distant from the L2, the problems that L2 learners have in decoding are larger. With her study van Boxtel showed that native-like attainment is possible for L2 learners and that the typological distance between the L1 and the L2 determines the ultimate success.

Schimke and Dimroth (2018) studied the acquisition of word order by child L2 and adult L2 learners of German by means of an EIT. In German the negation nicht follows the verb. Besides fillers, Schimke and Dimroth's EIT contained two types of sentences: grammatical sentences with the correct word order (verb + nicht) and ungrammatical sentences with the incorrect word order (nicht + verb). Each sentence had between 10 and 13 syllables, with an average of 12.5. When analyzing the data, Schimke and Dimroth encountered the same problem as van Boxtel, which is that there were sentences that in the repetition had been modified in a substantial way, because of the challenging nature of the task. Schimke and Dimroth decided to discard all sentences that did not contain nicht or the verb from the analysis. Their corpus therefore only contained "analyzable" sentences. The "analyzable" material contained identically repeated sentences (grammatical and ungrammatical), and sentences in which nicht and the verb were present, but in which the rest of the sentence had not been identically repeated.

Schimke and Dimroth (2018) distinguished different types of verbs in their study. Since the analyzable corpus contained an unequal number of items for each verb type, the scholars compared the two types of changes (verb + nicht $\rightarrow$ nicht + verb; nicht + verb $\rightarrow$ verb $+n i c h t)$ in percentages for each verb type, statistically analyzing the difference between the two types of changes. Their results showed similar patterns of development in the child and adult L2 learners, although children who had not fully acquired finiteness, i.e. subject-verb agreement, showed a preference for placing finite and non-finite lexical verbs, but not finite auxiliaries, right to negation. The influence of the type of verb ("light" or lexical) on word order with nicht has also been found by Verhagen (2011).

After the presentation of our research questions and our predictions in the next section, we will present our methodology, which will contain elements from both van Boxtel's (2005) and Schimke and Dimroth's (2018) methodology.

\section{Research questions, predictions, methodology and analysis}

\subsection{Research questions and predictions}

Whereas French uses a quantitative pronoun in elliptical quantitative constructions with a numeral, as in (2), English does not have one. This leads to the following research question:

(6) Do L1 English learners of Dutch produce ER significantly less often than L1 French learners of Dutch?

To answer the research question we used an EIT. According to van Boxtel (2005) the EIT is perfectly well suited to test the acquisition of phonologically non-salient 
elements. The task contained different types of conditions, and both grammatical and ungrammatical sentences, but, for ease of comparison with Berends et al.'s (2010) EIT study of the use of $E R$ in L1 child language, we will concentrate on grammatical sentences with ER only. Based on the difference between English and French, we can predict the following:

(7) When repeating correct quantitative constructions containing an elliptical noun phrase introduced by a numeral, i.e. sentences with $E R$, L1 English learners of Dutch will repeat $E R$ significantly less often than L1 French learners of Dutch.

\subsection{Methodology}

\subsubsection{Participants}

The participants in this test were the same as in Berends et al.'s (2017) and Berends et al.'s (2018) study on cross-linguistic influence in L2 acquisition of $E R$ tested by means of a GJT, see section 2. Besides 25 adult native speakers of Dutch (mean age 32;5, sd 15), there were 25 L1 French (mean age 47;0, sd 12) and 25 L1 English (mean age 48;11, sd 12) learners of Dutch. We only recruited advanced L2 learners (French: years of exposure 22;1, sd 11 and English: years of exposure 19;7, sd 13). General information about the participants, such as age and years of exposure, was collected via a questionnaire.

To be sure that the French and the English participants had acquired the minimum level of proficiency in Dutch that we required for participation, B2 or higher in the Common European Framework of Reference, we administered a Dutch proficiency task, the Test of Dutch Vocabulary (TDV). The test contained 60 items, gradually decreasing in frequency. The determination of frequency was based on information taken from CELEX (Baayen, Piepenbrock and Gulikers 1995). The participants had to choose between four potential synonyms, with "I really don't know" as a fifth option. The task was administered in E-prime. The results of the TDV showed that the French group scored slightly higher (mean score 41.6) than the English group (mean score 36.8). A direct comparison by means of a t-test between the French and the English groups did not reveal a significant difference between these two groups $(t=1.7027, p$-value $=0.0951)$.

\subsubsection{The Elicited Imitation Task}

The EIT was administered in E-prime. The test consisted of 12 experimental sentence pairs, presented in two versions, both in a randomized order. Among these sentences pairs there were 4 sentence pairs testing the use or omission of $E R$ in quantitative constructions with a numeral: the conditions "presence" and "absence". For each of these conditions there were two sentences. An example is given below. In the condition "presence" the introductory sentence was followed by a grammatical sentence containing $E R$. In the condition "absence" the introductory sentence was followed by an incorrect sentence in which $E R$ was missing. The introductory sentence did not have to be 
repeated by the participants. The sentences that had to be repeated contained between 17 and 19 syllables. The goal was to prevent the participants from simply relying on phonetic memory and from simply parroting.

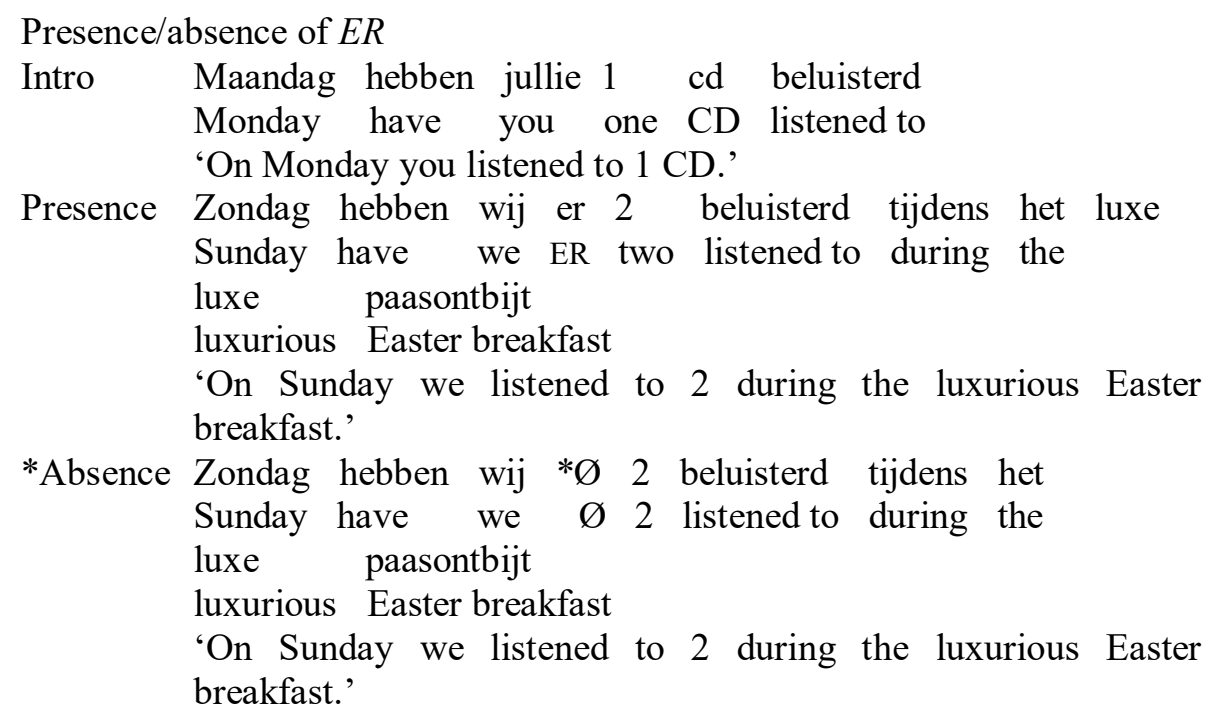

Besides the 12 experimental items, there were 8 distractor sentence pairs, which were only presented in a grammatical form, and which did not contain as many syllables as the experimental items, such as De tandarts heeft mijn tanden gebleekt, 'The dentist bleached my teeth' $\rightarrow$ Als ik nu lach stralen ze als een zonnetje 'If I smile now they shine like the sun'. The participants did not have to repeat the introductory sentence. Before the test started, two grammatical practice trials with feedback were offered. All of the participants correctly repeated at least one of the practice trials.

Contrary to the participants in van Boxtel's (2005) study, our participants were allowed to hear the sentences only one time. They were asked to repeat as much of the sentence as they remembered. They were told that it did not matter if they did not remember the whole sentence. This way we tried to avoid rote repetition. We did not ask them explicitly to repeat the sentences in correct Dutch - as, e.g. Erlam (2006) did in order to prevent high level learners from repeating grammatically incorrect sentences thinking that they were asked to do so - because we wanted the participants to focus more on the meaning than on the form of the sentences (Hulstijn and Hulstijn 1984). Furthermore, correction of ungrammatical sentences had to be spontaneous.

We did not explicitly ask the participants to wait some seconds before starting to repeat, because the length of the test sentences - with the target feature in the middle to complicate its memorization (Gallimore and Tharp 1981) - fulfilled this role (cf. Hamayan et al. 1977, who added a short explicative sentence to the test sentence to increase the memory load). However, in practice, because of the length of the sentences, the participants never immediately started to repeat the sentences, which shows that they needed some time to reconstruct the sentences, and were not simply parroting. 


\subsection{Analysis}

As was already announced in section 4.1, in the analysis we focus on the grammatical sentences of the condition "presence" only, see (8), for ease of comparison with the child data in Berends et al. (2010). In this test only grammatical sentences containing $E R$ were presented to the children. In the analysis of our results the repeated sentences were labelled precisely for accuracy, and, in the case of inaccurately repeated sentences, also for error types: A is the label for non-target-like responses with regard to $E R$; $\mathrm{B}$ is the label for target-like responses with regard to $E R$; $\mathrm{C}$ is the label for empty or nonsense responses; $\mathrm{D}$ is the label for doubling $(E R+$ noun$)$. $\mathrm{E}$ is the label for sentences that could not be scored because of the omission or modification of a crucial and obligatory part of the sentence (e.g. the quantifier). Since we were interested only in the $\mathrm{A}$ and $\mathrm{B}$ cases, we decided to discard the cases $\mathrm{C}, \mathrm{D}$ and $\mathrm{E}$ from the analysis, although for the sake of completeness we will present the cases C, D and E taken together as "other" in the table in the results section. In this way of analyzing the data, we follow Schimke and Dimroth (2018), who excluded the "other" cases as "unanalyzable" in their analysis of word order in German, and we differ from, e.g. Erlam (2006), who scored cases such as $\mathrm{D}$ and $\mathrm{E}$, and nonsense responses (category $\mathrm{C}$ ) as "incorrect", on a par with cases like A. Erlam (2006) scored empty responses (category C) as "missing data" and not as "incorrect". Following Schimke and Dimroth (2018), in the "presence" condition we distinguished the number of repetitions of $E R$, the number of incorrect omissions of $E R$ and the other cases.

The Dutch control group repeated the experimental sentences exactly, even the incorrect sentences. Although we had expected that the Dutch control group would correct the incorrect sentences, the fact that they repeated the sentences ad verbatim shows that the sentences were not too long to memorize. Although we will present the results of the Dutch control group for reference, we will not include the results of the L1 Dutch control group in the statistical analysis, but we will only compare the results of the L2 learners of Dutch with each other. This amounts to saying that we are only interested in the influence of the different L1s on the L2 (cf. van Boxtel 2005, Wu and Ortega 2013), but since we do not compare the L2 learners' data to the Dutch L1 data, it does not interest us to know if the answers given by the two groups of L2 learners are "target-like".

After scoring all the data, statistical analyses were performed in RStudio (version 3.5.2). We used a t-test to calculate if the two groups of L2 learners differ or do not differ significantly from each other.

\section{Results}

We present the results of the condition "presence" of $E R$ in table 1 . There were 25 L1 Dutch participants, 25 L1 French participants and 25 L1 English participants. For the condition "presence" there were two test sentences. We divide the answers into three groups: exact repetition, deterioration, i.e. omission of $E R$, and other cases. Since we are only interested in the first two cases, we compare only these two cases in percentages, cf. Schimke and Dimroth (2018) and Erlam (2006), who also presented the results in 
percentages because of the exclusion of a category "other" and "missing cases", respectively. The distinction of two complementary categories, A and B, also allows us to compare the results of the EIT to the results of the GJT, as analyzed in Berends et al. (2018). We give the p-value of the statistical analysis of the difference between the results of the L1 French and the L1 English learners of Dutch for these first two cases $(\mathrm{t}=2.0957, \mathrm{p}$-value $=0.03744)$, presenting the results of the L1 Dutch learners only for reference. Since after discarding the category "other" the percentages of the two other categories are complementary, the p-values for the two categories are the same:

Table 1. Comparison different groups in the condition "presence"

\begin{tabular}{|l|c|c|c|c|c|c|c|}
\hline & \multicolumn{2}{|c|}{ Dutch } & \multicolumn{2}{c|}{ French } & \multicolumn{2}{c|}{ English } & Fr-En \\
\hline & $\begin{array}{l}\text { absolute } \\
\text { number }\end{array}$ & $\%$ & $\begin{array}{l}\text { absolute } \\
\text { number }\end{array}$ & $\%$ & $\begin{array}{l}\text { absolute } \\
\text { number }\end{array}$ & $\%$ & p-value \\
\hline $\begin{array}{l}\text { Repetition } \\
E R\end{array}$ & 50 & $100 \%$ & 40 & $85 \%$ & 36 & $73 \%$ & 0.037 \\
\hline $\begin{array}{l}\text { Omission } \\
E R\end{array}$ & 0 & $0 \%$ & 7 & $15 \%$ & 13 & $27 \%$ & 0.037 \\
\hline Other & 0 & & 3 & & 1 & & \\
\hline
\end{tabular}

The number of "other" cases is relatively low. ${ }^{3}$ In the "presence" condition, the L1 English learners correctly repeated ER significantly less often than the L1 French participants. The L1 English learners also incorrectly omitted $E R$ significantly more than the L1 French learners.

\section{Discussion}

In this paper we investigated the acquisition of the quantitative pronoun $E R$ by L1 French and L1 English learners of L2 Dutch. Since French, just like Dutch, has a quantitative pronoun, which in the quantitative construction tested in this paper is used in the same way, and since English does not have one, we were interested to find out if English learners have more problems with the acquisition of the Dutch quantitative pronoun than the L1 French learners. To answer our research question we used an EIT containing grammatical sentences with $E R$. We predicted that the L1 English learners would omit $E R$ significantly more than the L1 French learners.

We discarded all "unanalyzable" answers, i.e. all sentences not containing $E R$ and a numeral (in this order). We divided the remaining sentences into "repetition" and "omission" of ER. This led to complementary percentages for these categories. We calculated if there was a significant difference between the results of the French and the English group of learners. Since the percentages for "repetition" and "omission" were complementary, the p-values for the two categories were identical.

\footnotetext{
${ }^{3}$ The percentages could also have been divided over the three categories, "repetition of $E R$ ", "omission of $E R$ " and "other". Since we were only interested in the first two categories we decided not to include the third category. Because of the low number of "other" cases, this does not change the overall results.
} 
Although we increased the number of syllables drastically with respect to the number of syllables in Berends et al.'s (2010) test that was used for the study of the acquisition of $E R$ by children, the Dutch control adults in our study repeated $E R$ in $100 \%$ of the cases, as they did in Berends et al.'s (2010) study. Since the number of syllables that we used in our test was the maximum of what has been proposed in the literature on EIT, our task cannot be considered to have been too easy for our L2 participants. Our results show that the French learners repeated $E R$ in $85 \%$ of the cases, whereas the English group repeated $E R$ in $73 \%$ of the cases, which is less than the adult L1 control group.

We predicted a significant difference between the French and the English learners, because whereas French is comparable to Dutch in using a quantitative pronoun in the "presence" condition, English differs from Dutch because it does not have a quantitative pronoun and allows for a "bare" quantitative construction. Our prediction was borne out. In the "presence" condition, the L1 English group repeated $E R$ significantly less often than the L1 French group and omitted $E R$ significantly more. Since a direct comparison of the two groups of L2 learners on the Dutch vocabulary test, the TDV, did not reveal a significant difference between the two groups, we assume that the significant difference between the two groups is not due to a difference in general proficiency in Dutch.

The results of the EIT suggest that the absence of a quantitative pronoun in English negatively hinders the acquisition of the quantitative pronoun construction in Dutch: it negatively influences the repetition of ER. Conversely, the results suggest that L1 French learners are advantaged by the fact that their language has a quantitative pronoun. It positively influences the repetition of $E R$ in correct sentences.

In section 2 we showed that with respect to a PET used to study the L1 acquisition of $E R$, an EIT provided better insights into the use or omission of $E R$ by the children (Berends et al. 2010). In the EIT $80.7 \%$ of the repetitions contained ER. The errors, $18.4 \%$, were almost all due to the omission of $E R$. As shown in section 2, for L2 acquisition a GJT did not reveal significant differences between L1 English and L1 French learners of Dutch in the "presence" condition, although this was predicted. In percentages the difference between the results of the French and the English groups were very small, the English group accepting $E R$ even slightly more than the French group ( $94 \%$ versus $91 \%$, respectively). However, the EIT used in the present study provided significant differences in the "presence" condition, as predicted.

Why should different types of tests yield different types of results? As for the PET and the EIT used in Berends et al.'s (2010) and van Hout et al.'s (2011) studies on L1 acquisition, the design of the PET left too much room for alternative responses. This was not the case in the GJT, since only the choice between "correct" and "incorrect" was given. Although there was a category "other", both in Berends et al. (2010) and in the present study for the EIT, only a low number of responses had to be included in this category in both studies. As for the different results for the GJT and the EIT in this study, we attribute them to the different nature of both tasks: our GJT was untimed, whereas in the EIT the participants could not wait too long before starting to quickly repeat the sentence, because of the memorization constraints. In this way the GJT tested explicit knowledge, whereas the EIT tested implicit knowledge (Ellis 2005, 2009b). According to DeKeyser (2003) and Ellis (2005, 2009a, 2009b), explicit knowledge is knowledge 
someone is aware of and it requires attentional control. Implicit knowledge is automatic (see also Hulstijn and de Graaff 1994). It may better represent the actual use of a construction by L2 learners in everyday situations. Munnich et al. (1994) reach the same conclusion on the basis of the comparison of these two types of test. A GJT gives us information about the learner's conscious knowledge, which may be based on what the learner has learned via prescriptive rules. The changes made in an EIT are unconscious and spontaneous, and therefore represent abstract grammatical knowledge. Our GJT was, like the EIT, aurally presented to the participants. Our results show that even in the aural GJT the L2 learners accepted the sentences containing $E R$ in a near native-like way: in more than $90 \%$ of the cases, not significantly differing from the native control group.

Diverging results for two different types of test were also found by van Boxtel et al. (2005). Whereas in the EIT there was a positive influence of a typologically more related L1 on native-like production of dummy subjects in L2 Dutch (see section 3), German and the French learners seemed to perform equally well in a Sentence Preference Task. Van Boxtel et al. also refer to Sabourin (2003: 152), who found that whereas German and Romance learners of Dutch performed natively in an offline GJT, in an ERP-study the German group had much more native-like ERP-patterns than the Romance group.

We only compared the L1 French and the L1 English learners, without a direct comparison with the L1 Dutch control group. Since we did not ask the participants to correct the sentences (as was done by Erlam 2006), in most of the cases the Dutch control group exactly repeated the incorrect sentences, although expressing that they knew that the sentences were incorrect, which shows that for adult L1 learners an EIT may not be an appropriate type of test. ${ }^{4}$ Although the L2 learners may also have tried to exactly repeat what they heard, the relatively higher number of incorrect omissions of $E R$ (L1 English) shows that there are fewer exact repetitions. ${ }^{5}$ We claim that this was because of the unconscious influence of their L1 on their repetitions. Since we did not compare the L2 learners' repetitions to those of the L1 control group, because of the presumed rote repetitions of the L1 Dutch group, we cannot claim that the French group is more target-like with respect to the use of $E R$ in the "presence" condition in Dutch than the English group, although if we take Dutch reference grammars or the Dutch linguistic literature as a reference, we could do so. The goal of this paper was simply to show the influence of the $\mathrm{L} 1$ on the acquisition of the quantitative pronoun, which we hope to have shown.

We only compared the French and the English groups in the condition "presence", because we wanted to investigate if Berends et al.'s (2010) positive results for the use of an EIT for the acquisition of $E R$ by children would be confirmed for L2 research. The complete EIT tested several other conditions. For most of these contexts also more

\footnotetext{
${ }^{4}$ For the L1 Dutch group the absolute numbers were 43, 7, 0 in the "absence" group, i.e. ungrammatical sentences not containing $E R$. The first number represents exact repetition, the second number represents insertion of $E R$, and the third number represents the "other" cases.

${ }^{5}$ In the "absence" condition, i.e. the ungrammatical sentences without $E R$, the French group corrected the sentence 19 times (out of 49), i.e. in $39 \%$ of the cases, which also shows that they did not exactly repeat the sentences, but recontructed the sentence (cf. Erlam 2006). The English group inserted $E R$ in these sentences in only $12.5 \%$ of the cases ( 6 times out of 48$)$. This difference is significant $(t=4.4905$, $\mathrm{p}$-value $=1.294 \mathrm{e}-05)$.
} 
influence of L1 English on L2 Dutch was detected than in Berends et al.'s (2018) GJT. For the complete results, see Berends (in progress).

Since the condition "presence" was part of a larger test, the number of test items for this condition was low. In future research it may be investigated if our results would remain the same if the number of test items is augmented.

\section{Conclusion}

Whereas in a quantitative construction with noun ellipsis and a remnant numeral Dutch and French use a quantitative pronoun, English does not have one. Earlier results have shown that, in a Grammaticality Judgment Task, French and English learners of L2 Dutch did not differ significantly from each other in the acceptance of $E R$ in this type of construction, although this was predicted.

In this paper we tested the repetition of $E R$ in a quantitative construction by adult French and English learners of Dutch in an Elicited Imitation Task, a type of task that has been argued to be a suitable task to study the L1 acquisition of the Dutch quantitative pronoun by children. The French learners repeated the Dutch quantitative pronoun significantly more often than the English learners. We attributed the difference between the results with the GJT to the different nature of the tests, the GJT testing explicit knowledge and the EIT testing implicit knowledge. Our results suggest that while the two groups of learners do not differ in their judgments of the acceptability of the presence of the quantitative pronoun in sentences containing a quantitative construction with noun ellipsis, the absence of a quantitative pronoun in English negatively influences their production of the pronoun in Dutch, whereas the presence of a quantitative pronoun in French leads to positive transfer.

An interesting question would be if bilingual French-Dutch and English-Dutch children would also show a difference in their production of the quantitative pronoun in Dutch. We leave this question for future research.

\section{References}

Baayen, R. H., Piepenbrock, R. and Gulikers, L. 1995. The CELEX Lexical Database (CD-ROM). Linguistic Data Consortium, University of Pennsylvania, Philadelphia, PA.

Bennis, H. 1986. Gaps and Dummies. Dordrecht: Foris.

Berends, S. In progress. Complexity in the Acquisition of the Dutch Quantitative Pronoun ER. PhD dissertation, University of Amsterdam.

Berends, S., Hulk, A. and Sleeman, P. 2016. The emergence of the pronouns Dutch er and French en in child L1 and the role of complexity. Language Sciences 60: 144-159.

Berends, S., Schaeffer, J. and Sleeman, P. 2017. Cross-linguistic influence in adult second language learners: Dutch quantitative pronoun constructions. In M. LaMendola and J. Scott (eds.), BUCLD 41: Proceedings of the 41st Annual Boston University Conference on Language Development, 74-87. Somerville, MA: Cascadilla Press.

Berends, S., Sleeman, P., Hulk, A. and Schaeffer, J. 2018. Methodological issues in experimental L2 acquisition: Differences between production and comprehension. Paper presented at the conference "Research methodology in the field of second language acquisition and learning", 30 May-1 June 2018, Montpellier. 
Berends, S., Veenstra, A. and van Hout, A. 2010. Nee, ze heeft er twee. Acquisition of the Dutch quantitative er. Groninger Arbeiten zur germanistischen Linguistik 51: 1-7.

Bley-Vroman, R., Chaudron, C. 1994. Elicited imitation as a measure of second-language competence. In E. Tarone, S. Gass and A. Cohen (eds.), Research Methodology in Second-Language Acquisition, 245-261. Hillsdale, NJ: Lawrence Erlbaum.

van Boxtel, S. 2005. Can the Late Bird Catch the Worm? Ultimate Attainment in L2 Syntax. PhD dissertation, Radboud University Nijmegen. LOT Dissertations 109.

van Boxtel, S., Bongaerts, T. and Coppen, P.-A. 2005. Native-like attainment of dummy subjects in Dutch and the role of the L1. International Review of Applied Linguistics in Language Teaching (IRAL) 43 (4): 355-380.

Brown, R., Fraser, C. 1964. The acquisition of syntax. Monographs of the Society for Research in Child Development 29: 64-100.

DeKeyser, R. 2003. Implicit and explicit learning. In C. J. Doughty and M. H. Long (eds.), Handbook of Second Language Acquisition, 313-348. Malden, MA: Blackwell.

Devescovi, A., Caselli, M.C. 2007. Sentence repetition as a measure of early grammatical development in Italian. International Journal of Language \& Communication Disorders 42 (2): 187-208.

van Dijk, C., Coopmans, P. 2013. On the acquisition of 'daar' and 'er'. Linguistics in the Netherlands 30 (1): 73-88.

Ellis, R. 2005. Measuring implicit and explicit knowledge of a second language: A psycho-metric study. Studies in Second Language Acquisition 27: 141-172.

Ellis, R. 2009a. Implicit and explicit learning, knowledge and instruction. In R. Ellis, S. Loewen, C. Elder, R. Erlam, J. Philp and H. Reinders (eds.), Implicit and Explicit Knowledge in Second Language Learning, Testing and Teaching, 3-25. Bristol: Multilingual Matters.

Ellis, R. 2009b. Investigating learning difficulty in terms of implicit and explicit knowledge. In R. Ellis, S. Loewen, C. Elder, R. Erlam, J. Philp and H. Reinders (eds.), Implicit and Explicit Knowledge in Second Language Learning, Testing and Teaching, 143-166. Bristol: Multilingual Matters.

Erlam, R. 2006. Elicited imitation as a measure of L2 implicit knowledge: An empirical validation study. Applied Linguistics 27 (3): 464-491.

Gallimore, R., Tharp, R. 1981. The interpretation of elicited imitation in a standardized context. Language Learning 31: 369-392.

Hamayan, E., Saegert, J. and Laraudee, P. 1977. Elicited imitation in second language learners. Language and Speech 20: 86-97.

Hout, A. van, Veenstra, A. and Berends, S. 2011. All pronouns are not acquired equally in Dutch: Elicitation of object and quantitative pronouns. In M. Pirvulescu, M. C. Cuervo, A. T. Pérez-Leroux, J. Steele and N. Strik (eds.), Selected Proceedings of the 4th Conference on Generative Approaches to Language Acquisition North America (GALANA 2010), 106-121. Somerville, MA: Cascadilla Press.

Hulstijn, J., de Graaff, R. 1994. Under what conditions does explicit knowledge of a second language facilitate the acquisition of implicit knowledge? A research proposal. AILA Review 11: 97-113.

Hulstijn, J., Hulstijn, W. 1984. Grammatical errors as a function of processing constraints and explicit knowledge. Language Learning 34: 23-43.

Jensen, E.D., Vinther, T. 2003. Exact repetition as input enhancement in second language acquisition. Language Learning 53 (3): 373-428.

Lenneberg, E. 1967. Biological Foundations of Language. New York: John Wiley.

MacWhinney, B. 2006. The CHILDES Project: Tools for Analyzing Talk, third edition. Mahwah, NJ: Lawrence Erlbaum Associates.

McDade, H.L., Simpson, M.A. and Lamb, D.E. 1982. The use of elicited imitation as a measure of expressive grammar: A question of validity. Journal of Speech and Hearing Disorders 47 (1): 19-24.

van Moere, A. 2012. A psycholinguistic approach to oral language assessment. Language Testing 29 (3): 325-344.

Munnich, E., Flynn, S. and Martohardjono, G. 1994. Elicited imitation and grammaticality judgements tasks: What they measure and how they relate to each other. In E. Tarone, S. Gass and A. Cohen (eds.), Research Methodology in Second Language Acquisition 227-243. Hillsdale, NJ: Lawrence Erlbaum.

Penfield, W. and L. Roberts. 1959. Speech and Brain Mechanisms. Princeton, NJ: Princeton University Press.

RStudio Team. 2015. RStudio: Integrated Development for R. RStudio Inc., Boston MA. http://www.rstudio.com. 
Sabourin, L. 2003. Grammatical Gender and Second Language Processing: An ERP study. PhD dissertation. Groningen: Groningen University Press.

Schimke, S. and Dimroth, C. 2018. The influence of finiteness and lightness on verb placement in L2 German: Comparing child and adult learners. Second Language Research 34 (2): 229-256.

Sleeman, P., Hulk, A. 2013. L1 acquisition of noun ellipsis in French and in Dutch: Consequences for linguistic theory. In S. Baauw, F. Drijkoningen, L. Meroni, M. Pinto (eds.), Romance Languages and Linguistic Theory 2001. Amsterdam/Philadelphia: John Benjamins.

Verhagen, J. 2011. Verb placement in second language acquisition: Experimental evidence for the different behavior of auxiliary and lexical verbs. Applied Psycholinguistics 32: 821-58.

Vinther, T. 2002. Elicited imitation: A brief overview. International Journal of Applied Linguistics 12 (1): $54-73$

Wu, S., Ortega, L. 2013. Measuring global oral proficiency in SLA research: A new elicited imitation test of L2 Chinese. Foreign Language Annuals 46 (4): 680-704.

Yan, X., Maeda, Y., Lv., J. and Ginther, A. 2016. Elicited imitation as a measure of second language proficiency: A narrative review and meta-analysis. Language Testing 33 (4): 497-528. 